\title{
Sensor Array Based on Metal-Decorated Carbon
}

\author{
Nanotubes
}

Alexander Star*, Vikram Joshi, Sergei Skarupo, David G. Thomas, and Jean-Christophe P. Gabriel

\section{Supporting Information}

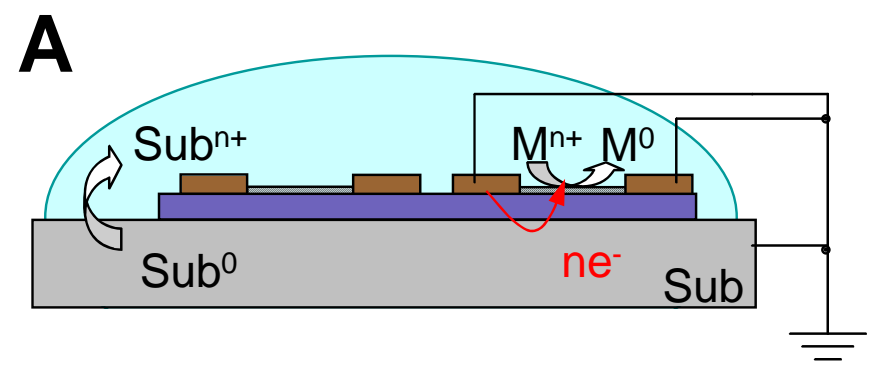

Computer with LabVIEW based
Data Acquisiton System
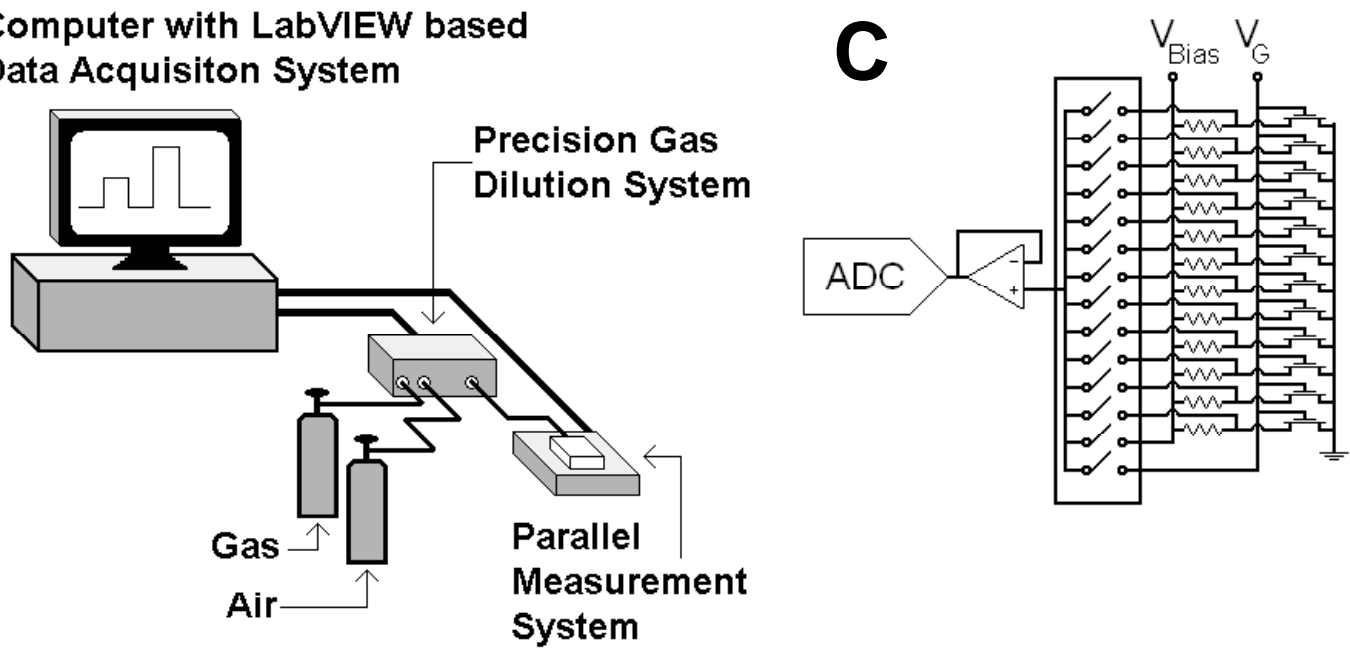

Figure S1. (A) Fabrication of a sensor array by galvanic displacement: The surface of the substrate (Sub) serves as the reducing agent and electron source for reduction of the metal (M) salt. Site-specific metal nanoparticles deposition was achieved by holding selected NTFET device at the same potential as the substrate. (B) Schematic drawing of parallel measurement system (PMS) operation for sensor array testing. (C) Schematic of electronic measurement scheme of PMS, consisting of resistors, switches, and analog-to-digital converter (ADC). 

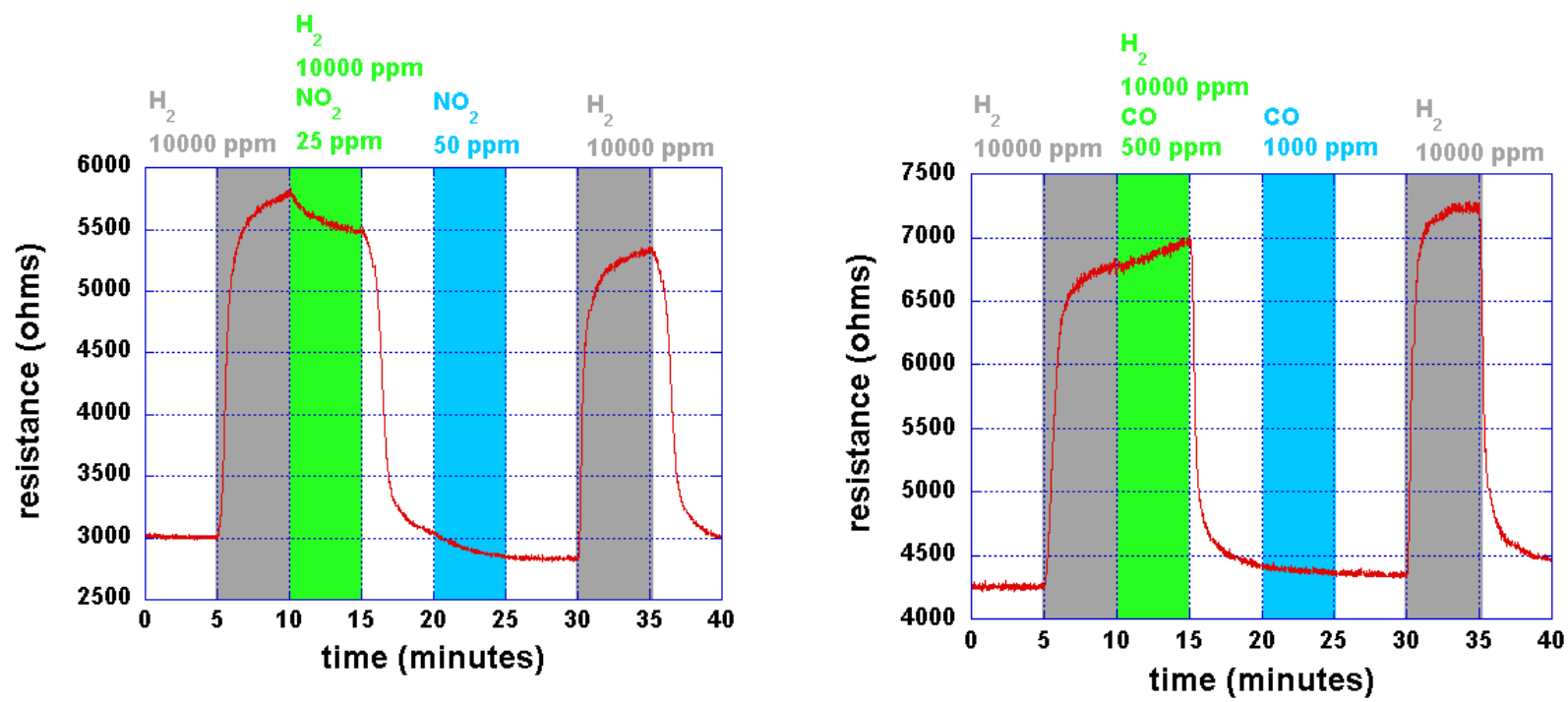

Figure S2. Source-drain resistance of metal decorated NTFET in air upon exposure to $\mathrm{H}_{2}$ gas (5-10 min), to mixture of $\mathrm{H}_{2}$ gas and interference gas (10-15 min), to second gas alone (20-25 min), and to $\mathrm{H}_{2}$ gas again (30-35 min). Changes in the NTFET resistance as a result of the presence of the second gas indicate cross sensitivity. After resistance recovery, there is exposure to second gas alone in order to measure a false alarm. The last exposure to $\mathrm{H}_{2}$ is designed to estimate NTFET's reproducibility and can be used as indication of device poisoning and drift.

Table S1. Metal-decorated NTFET sensing binary gas mixtures: $\mathrm{H}_{2}(10,000 \mathrm{ppm}) / \mathrm{second}$ gas in air:

\begin{tabular}{|c|c|c|c|}
\hline Second gas & Concentration $^{(a)}$ & $\begin{array}{c}\text { Cross } \\
\text { Sensitivity }\end{array}$ & $\begin{array}{c}\text { False } \\
\text { Alarm }\end{array}$ \\
\hline Carbon Monoxide (CO) & $500-1,000 \mathrm{ppm}$ & $+9 \%$ & 0 \\
\hline Hydrogen Sulfide $\left(\mathrm{H}_{2} \mathrm{~S}\right)$ & $25-50 \mathrm{ppm}$ & 0 & 0 \\
\hline Ammonia $\left(\mathrm{NH}_{3}\right)$ & $50-100 \mathrm{ppm}$ & 0 & 0 \\
\hline Nitrogen Dioxide $\left(\mathrm{NO}_{2}\right)$ & 25-50 ppm & $-11 \%$ & $-500 \mathrm{ppm}$ \\
\hline Methane $\left(\mathrm{CH}_{4}\right)$ & $12,500-25,000 \mathrm{ppm}$ & 0 & 0 \\
\hline
\end{tabular}

(a) Gas concentrations are presented in parts per million (ppm). Lower gas concentrations were used for measuring the cross sensitivity, higher gas concentrations were tested for false alarms.

(b) Change in NTFET resistance compare to $\mathrm{H}_{2}(10,000 \mathrm{ppm})$ response.

(c) Response to the second gas expressed in ppm of $\mathrm{H}_{2}$. 

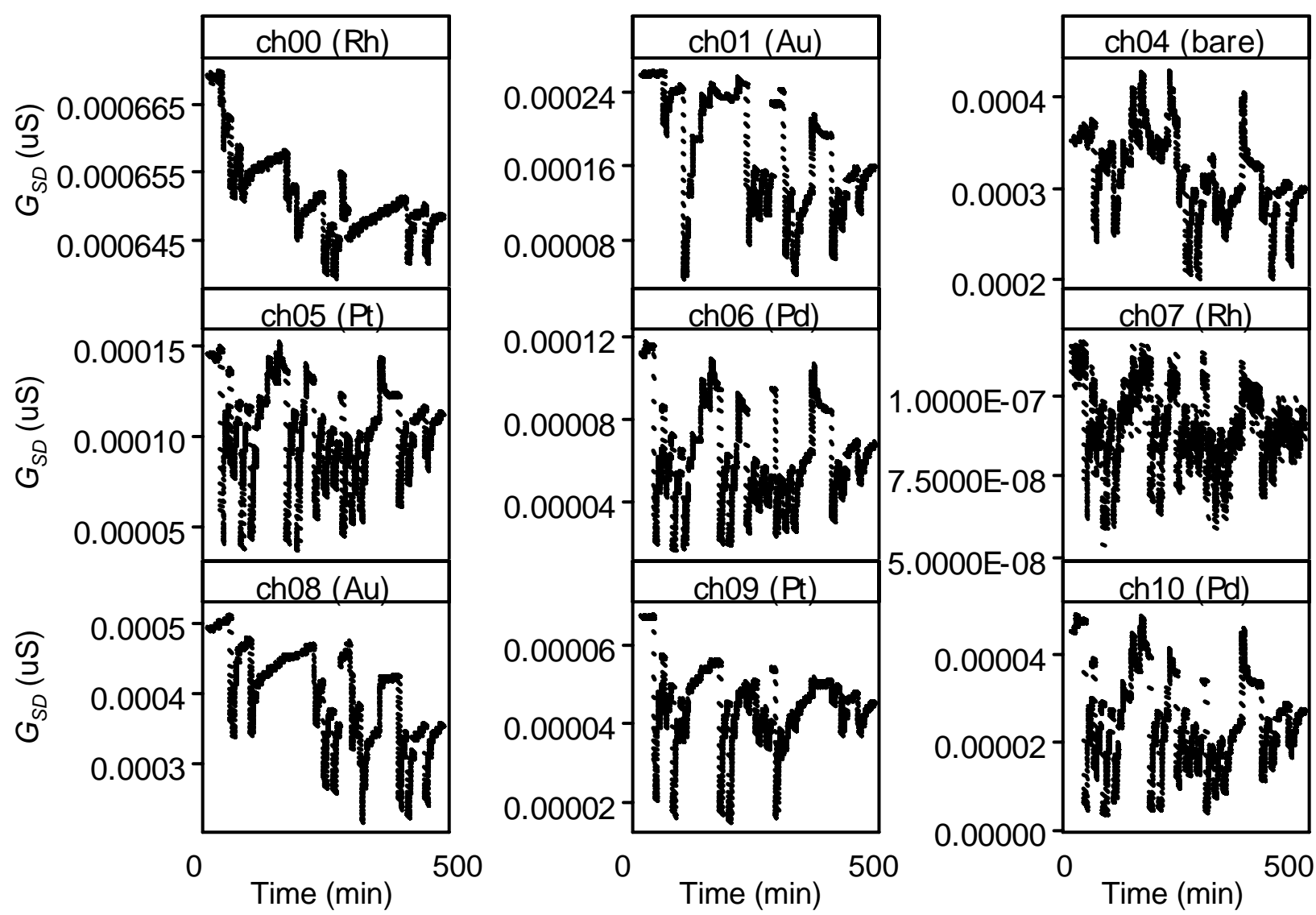

Figure S3. Measurements of multiple channels during the sequence of 25 gas exposures $\left(\mathrm{CO}, \mathrm{H}_{2}, \mathrm{NH}_{3}\right.$, $\mathrm{H}_{2}, \mathrm{H}_{2} \mathrm{~S}, \mathrm{NO}_{2}, \mathrm{NO}_{2}, \mathrm{NO}_{2}, \mathrm{H}_{2}, \mathrm{H}_{2}, \mathrm{NO}_{2}, \mathrm{H}_{2} \mathrm{~S}, \mathrm{NH}_{3}, \mathrm{NH}_{3}, \mathrm{H}_{2}, \mathrm{H}_{2} \mathrm{~S}, \mathrm{H}_{2} \mathrm{~S}, \mathrm{CO}, \mathrm{NO}_{2}, \mathrm{CO}, \mathrm{H}_{2} \mathrm{~S}, \mathrm{NH}_{3}, \mathrm{CO}$, $\mathrm{NH}_{3}, \mathrm{CO}$ ). Abscissa: time, minutes. Ordinate: conductance, Siemens. Three channels are not shown.

A single gas exposure consisted of a five-minute settling period, five-minute exposure to gas followed by a ten-minute recovery period. Selected animations of the full G-Vg curves recorded during single gas exposures and corresponding conductance ( $\mathrm{G}$ at $\mathrm{Vg}=0$, blue curve) are attached here as AVI files.

\section{Sensor Array Data Analysis}

The PCA method allows one to represent most of the variance in fewer dimensions. An ordered orthogonal basis is calculated, where the first basis vector corresponds to the largest variance in the original data, the second to the second largest variance and so on. The PCA loadings (Figure S4A) are the coefficients used to rotate the data, and indicate the relative importance of the original vectors (measurement channels in our case). The scores represent the position of the data points in the new vector space. Typically, the scores for the first two components are plotted. However, in this case, the third component is still relatively important. Responses to $\mathrm{H}_{2}, \mathrm{H}_{2} \mathrm{~S}, \mathrm{NH}_{3}$, and $\mathrm{NO}_{2}$ gases lie in separate regions of the space of the first three principal components (Figure S4B), whereas response to CO is less defined, indicating larger error in detection of this gas by the sensor array.

One of the main steps is that of data reduction, or variable selection. Different methods exist, ${ }^{26}$ many of which involve linear transformation of the predictor matrix and variable selection based on the transformed data. It is worth noting that we did not restrict the number of components in the model, and 
the algorithm selected all nine principal components, which are linear transformations of data from the selected nine measurement channels. This means that in this case nothing was discarded from the original dataset and that the resulting model is identical to that of the classic multivariate linear regression.
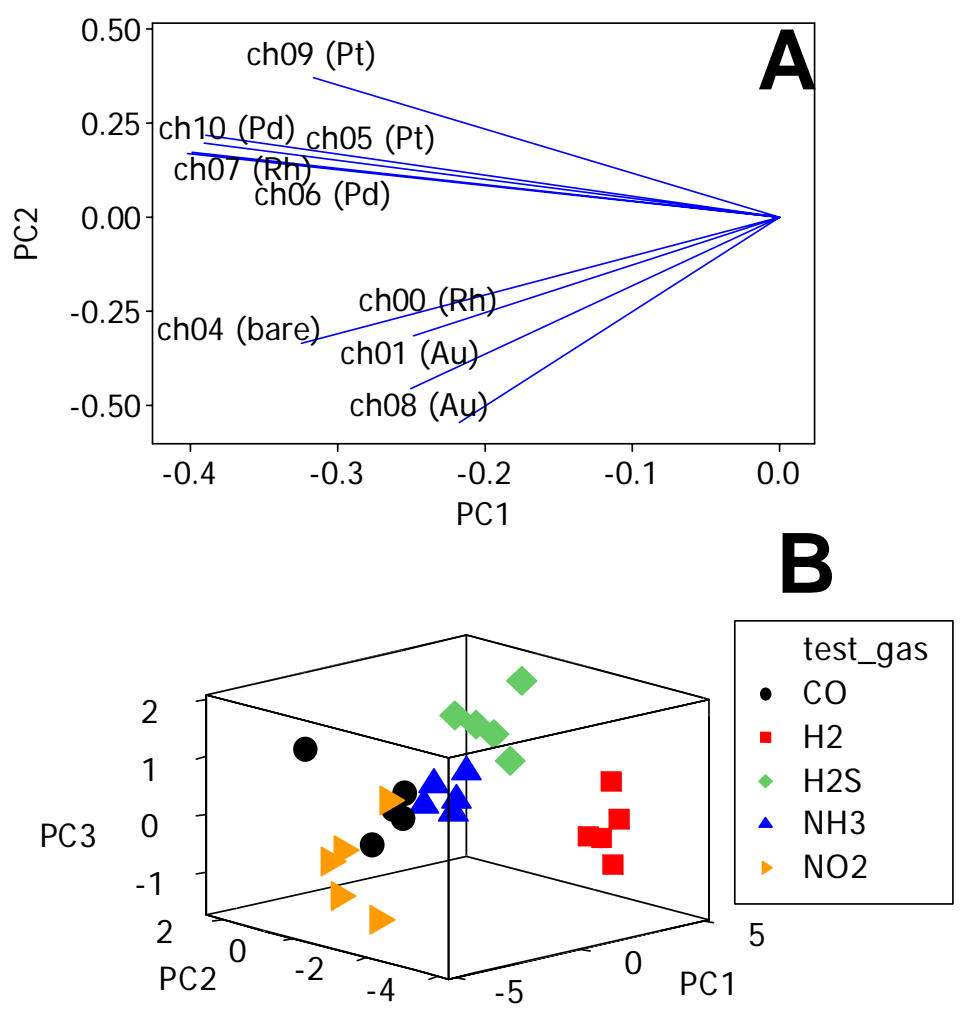

Figure S4. Principal Component Analysis (PCA) of the sensor array which was prepared by metal electroplating. Total of 10 channels (two for each metal and two for bare NTFET devices) were measured during exposure to the sequence of 25 gas exposures as summarized in Table 1. (A) PCA loadings of multiple measurement channels for the first two components. (B) Scores as 3-D plot for the first three components. Points corresponding to zero test gas concentration are not shown for clarity (however, they were used in the analysis and affected the basis selection). 